\title{
Transposición de El húsar de la muerte de Pedro Sienna por el colectivo La Patogallina
}

\author{
Transposition of El húsar de la muerte \\ of Pedro Sienna by La Patogallina Collective
}

\author{
Isabel Sapiaín Caro \\ Universidad de Buenos Aires \\ isapiainc@gmail.com \\ Carla Cortez Cid \\ Universidad de Buenos Aires \\ carlacimarrona@gmail.com
}

\section{Resumen}

Este trabajo analiza la "adaptación" del filme El húsar de la muerte de Pedro Sienna, realizada por el colectivo La Patogallina. Se explora el vínculo entre ambas obras desde la transposición; la relación entre el lenguaje cinematográfico silente y el teatral, así como los alcances políticos de la obra de teatro. Para ello, se repara en la celebridad de película, en la popularidad del personaje Manuel Rodríguez, en las características de la obra de teatro y en las operaciones narrativas y estéticas de la transposición. Con ello, La Patogallina construiría una pieza que homenajea tanto el código del cine silente desde el lenguaje teatral como a la figura de Manuel Rodríguez, actualizando su sentido político y el de su lucha en el Chile contemporáneo.

Palabras clave: transposición, El húsar de la muerte, lenguaje teatral, cine silente, actualización.

\begin{abstract}
This work analyzes the "adaptation" of the film El húsar de la muerte of Pedro Sienna made by La Patogallina collective. It explores the link between both pieces from the transposition viewpoint, the relationship between the silent cinematographic language and the theatrical one, and the political aftermaths of the theater piece. For such reasons, it notes the success achieved by the movie, the popularity of the character Manuel Rodriguez, the characteristics of the play and the narrative and aesthetics operations of the transposition. With this, La Patogallina would build a piece that celebrates both the silent cinema code from the theatrical language and the figure of Manuel Rodriguez, updating its political meaning and that of its fight in contemporary Chile.
\end{abstract}

Keywords: transposition, El húsar de la muerte, theatrical language, silent cinema, update. 
En el amplio mundo del arte, pero específicamente en el moderno y contemporáneo, nos encontramos con muchas citas, referencias e interconexiones entre distintas obras artísticas. Desde el surgimiento del cine, se vio en él la posibilidad de poner en la pantalla grande diversos textos dramáticos y literarios; primero confiando en la ilusión de realidad y verosimilitud que podía conferirse usando el lenguaje cinematográfico, luego comprendiendo que el filme podía despegarse del texto fuente tanto como se quisiera. La mayoría de las veces se ha tratado de la transformación lingüística de textos narrativos y dramáticos al lenguaje cinematográfico, sin embargo también existen otro tipo de transposiciones menos frecuentes, como la que abordaremos en este trabajo, que corresponde a la transposición efectuada por el colectivo artístico chileno La Patogallina en su obra teatral El húsar de la muerte (2000), basada en la obra fílmica homónima de Pedro Sienna (1925).

Precisamente, la obra de La Patogallina constituye un caso particular dentro de las transposiciones, que como señalamos comúnmente implican el "paso" del texto literario al texto fílmico. Así, aquí se trata de una transposición, si se quiere, "a la inversa" con respecto al proceso creativo que habitualmente se realiza, pues en este caso la obra originaria es una película de cine silente, mientras la transposición, una obra teatral (y no literaria). Ambas tratan sobre las hazañas del héroe chileno del periodo de la Independencia, Manuel Rodríguez (1785-1818).

Este trabajo surge desde la inquietud por preguntarnos sobre las relaciones entre el cine y el teatro propuestas por la compañía en esta obra. Así, nos interrogamos por la lectura que hace La Patogallina del filme, y constituye nuestro propósito analizar el vínculo entre ambas creaciones, la relación entre el lenguaje cinematográfico y el teatral, y los alcances políticos de la propuesta. En este sentido, creemos que la transposición realizada por La Patogallina actualizaría la obra de Sienna y la figura histórico-legendaria de Manuel Rodríguez al insertar elementos propios del contexto sociopolítico actual para recrear la figura del héroe controvertido que se sitúa al margen del poder, cargándola de un nuevo sentido político. A ello agregamos que esta actualización se llevaría a cabo al homenajear y reconfigurar la estética del cine silente desde el lenguaje teatral, lográndose un código que asimila la matriz del cine mudo.

Para abordar cómo La Patogallina transpone El húsar de la muerte, hemos dividido este escrito en tres apartados. Primero, situamos teóricamente lo que entendemos por transposición; luego, revisamos los antecedentes del filme de Pedro Sienna; en tercer lugar, presentamos el trabajo de la compañía, la obra y el análisis en sí de la transposición. Comprendiendo que la obra de teatro es una obra independiente, y que dedicarnos a contrastarla con la película escena por escena sería reducir la puesta a un mero derivado del texto fuente, hemos optado por analizar escenas y operaciones artísticas de la pieza — a la luz del filme-, agrupándolas en dos ejes de desarrollo, que creemos enmarcan los propósitos que la obra de La Patogallina trae por sí misma. Estos son: a) Manuel Rodríguez y la reivindicación del héroe desde 
lo popular y b) Reivindicación de la memoria cinematográfica ${ }^{1}$ y transposición del lenguaje del cine silente. Ambos ejes están cruzados por la actualización histórica y la apropiación del lenguaje cinematográfico.

\section{La transposición: autonomía y vínculo entre obras}

Considerando que los teóricos de la transposición a cuyos planteamientos recurrimos se refieren al vínculo entre la literatura y el cine, hemos de hacer la salvedad de que las herramientas y citas que tomamos de sus propuestas se focalizan precisamente en ese tipo de transfiguración y en ese orden. Por lo tanto, consideramos sus planteamientos con mayor apertura, como un punto de partida que resulta oportuno para las relaciones que nos interesan aquí: entre el cine, como lenguaje originario, y luego, el teatro.

Los estudios acerca de las relaciones entre cine y literatura han dado paso a diversas ideas y cuestionamientos sobre cómo entender este objeto de estudio, su análisis y también su terminología, debatiéndose entre la pertinencia de conceptos como "adaptación", "traducción", "transposición”, etc. Al respecto, nos inclinamos por este último, ya que de acuerdo con Adriana Cid la palabra "coloca el acento en el proceso (creador) que se opera en el pasaje del medio literario al medio fílmico" (24), a lo que sumamos el planteamiento de Sergio Wolf, para quien el vocablo "designa la idea de traslado pero también la de trasplante, de poner algo en otro sitio, de extirpar ciertos modelos, pero pensando en otro registro o sistema" (16). Así, al hablar de transposición partimos del supuesto de que, dado que la literatura -el teatro en nuestro caso- y el cine constituyen disciplinas autónomas que se deben a sus propios lenguajes, al existir la relación entre una obra primera en la cual se basa una segunda, en la transposición se construye un nuevo objeto, justamente, desde otro lenguaje, otro formato (Wolf 30). En consecuencia, no se trata de una relación de sumisión en la que un segundo "texto" debe mantener dentro de lo posible el formato del primero, "respetando" el sentido de primer código, o de hallar equivalencias, que sería lo que ocurre al pensar el fenómeno como traducción (Wolf 30), de comparar qué cambió y qué se mantuvo; o de pensar que hay que homologar un formato a otro, moldeándolo para que "quepa" en un segundo, que sería lo que ocurre al pensar en la "adaptación" (Wolf 15). Por lo tanto, tal como han planteado

1 Fernanda Carvajal y Camila van Diest señalan que con este montaje la compañía tiene un gesto de recuperar nuestra "memoria audiovisual" (259). Hemos tomado prestada la expresión para modificarla por "memoria cinematográfica", en virtud de que creemos que La Patogallina se enfoca en el cine y que nos interesa dar cuenta precisamente de la adopción y recreación de elementos del lenguaje cinematográfico que realiza la compañía.

2 O, en nuestro caso, del medio fílmico al medio teatral. Esta y las siguientes citas sobre la comprensión de la transposición las interpretamos considerando la inversión del orden de los textos (literario y fílmico), pero, además, pensando en el lenguaje teatral en donde se hable del lenguaje literario. 
Adriana Cid, Sergio Wolf o José Luis Sánchez Noriega, ${ }^{3}$ no creemos adecuado pensar el análisis desde ideas como la legitimidad/calidad de la obra transpuesta según su "fidelidad" al original, de lo que se desprende el supuesto de que no ser "fiel" o "leal" constituye una traición (y lo que supone, por añadidura, la mayor calidad artística de la obra fuente, que por lo general es literaria, es decir, un mayor prestigio dado por la tradición).

Por consiguiente, partimos de suponer que ambas obras son entidades aparte tejidas gracias a sus lenguajes, entre las cuales se genera un diálogo a partir de la obra que transpone a la primera, la cual, ciertamente, efectúa una relectura y una transformación conforme a ciertas decisiones de sus creadores. Al respecto, creemos que tienen sentido las siguientes palabras de Adriana Cid:

[...] toda transposición fílmica habrá de ser comprendida como resultante de un complejo proceso creador, de transformación transmedial, que no se limita a meras operaciones mecánicas de trasvase, sino que lleva impreso el sello inconfundible de su autor. En cierto momento de la génesis y realización del film o previo a él, se produce — casi mágicamente, estoy tentada a afirmar - una intersección de horizontes entre ambos artistas, el escritor y el cineasta, y de ese encuentro, brota una (re)lectura singular del texto literario. [...] No se trata entonces de relaciones jerárquicas de prestigio, en las que el cine aparece como un arte menor que se nutre de la literatura para afianzarse, sino de identidades distintas que establecen una relación especular e independiente a la vez (28).

Justamente, en el concepto de "transformación transmedial" subyace la comprensión de que ambas obras obedecen a medios — sistemas, formatos, lenguajes - distintos; de allí que traigan consigo el "sello" de sus autores. Por otra parte, Cid repara en otro aspecto, que es la relación "especular e independiente a la vez" entre ambos productos, los que confluyen y divergen según voluntades estéticas dispares remitiendo de algún modo al otro. Este vínculo especular es expresado elocuentemente por Wolf al señalar que la transposición consiste "En cómo olvidar recordando" (el énfasis es del original), frase que ilustra la paradoja que opera al ser testigos de que se ha creado algo nuevo que (no) se debe a una fuente, de la "dificultad materialmente insoluble de que aquello que preexiste desaparezca permaneciendo" (77).

3 Sánchez Noriega, sin embargo, refiere más libremente la sinonimia entre algunos términos: "Hablaremos indistintamente de adaptar, trasladar o transponer para referirnos al hecho de experimentar de nuevo una obra en un lenguaje distinto a aquel en que fue creada originalmente", y en general habla de "adaptación" cuando se trata de "textos literarios y fílmicos que cuenten la misma historia" (47), si bien lo hace entendiendo que la literatura y el cine son sistemas distintos, no analogables. Asimismo, usa el término "transposición" para catalogar a un tipo específico de "adaptación". 


\section{Antecedentes de Pedro Sienna y del filme}

Pedro Sienna (Pedro Pérez Cordero), nacido en 1893, fue un artista multidisciplinario que se dedicó a la dramaturgia, actuación, producción y dirección cinematográfica, así como al periodismo y la crítica de arte. En 1920 protagonizó la película Manuel Rodríguez, dirigida por el cineasta argentino Arturo Mario, y cuyo argumento estaba basado en la novela de Alberto Blest Gana Durante la reconquista (1897). De allí habría quedado con la idea de realizar su propia versión sobre el personaje, la que fue filmada en 1925 en los estudios de Andes Films.

El húsar de la muerte es una de las cuatro películas chilenas (de mayor metraje) del periodo silente chileno que se conserva en la actualidad, ${ }^{4}$ y es la más conocida de todas ellas. Sin embargo, el filme ha experimentado algunas modificaciones hasta llegar a nosotros. En 1941 fue reestrenada y se sustituyeron los intertítulos originales por subtítulos sobre la imagen. Junto a esto se recortó el encuadre original de la imagen muda para insertar la banda de sonido óptico, por lo que la imagen original quedó mutilada. Además, se incorporó un final nuevo de corte patriótico, que muestra un desfile militar. En 1962 el documentalista Sergio Bravo junto a Daniel Urria realizaron una nueva restauración, con la asesoría de Pedro Sienna, en la que repusieron los intertítulos originales y retiraron el final incluido en 1941. De esta versión se obtuvieron los duplicados negativos y una copia $16 \mathrm{~mm}$ silente, que quedaron almacenados en la Cineteca de la Universidad de Chile. En 1964, la Cineteca de la Universidad de Chile confió la musicalización de la película a Sergio Ortega.

Durante la dictadura, tras el cierre de la Cineteca, la copia de nitrato y los negativos se extraviaron por años. Luego, en 1994, la División de Cultura del Ministerio de Educación financia un segundo proceso de restauración para obtener una copia en $35 \mathrm{~mm}$. En este proceso se reemplazan los intertítulos originales por otros textos nuevos y se agrega el final que no corresponde a la versión muda. La composición de Ortega es retirada, y se encomienda una nueva al músico Horacio Salinas. Esta es la versión que más ha circulado.

Finalmente, el 2009 la refundada Cineteca de la Universidad de Chile decide recuperar la música creada por Ortega para la película. En octubre del año 2009, la Cineteca reestrenó dicha versión, sin embargo la copia que ha circulado de manera más masiva, y en la que basamos nuestro trabajo investigativo, es la de 1995, incorporada en el Archivo Digital de la Cineteca Nacional.

El húsar de la muerte, cuyo argumento fue escrito por el propio Sienna junto a Hugo Silva, es una obra que ha suscitado gran interés en el transcurso de la historia del cine chileno, pues retrata de forma amena al héroe Manuel Rodríguez y su participación

4 Las otras son Canta y no llores, corazón, o el precio de una honra (1925) de Juan Pérez Berrocal, Leopardo (1926) de Alfredo Llorente y la recientemente restaurada Incendio (1926) de Carlos del Mudo. 
en la lucha por la independencia del país a principios del siglo xIX. Además, tal como plantea Jorge Ruffinelli, se trata de una obra con bastante humor popular, de narrativa ágil y de una

[...] sutil combinación de (a) film didáctico sobre un héroe de la patria, (b) ejemplo "latinoamericano" de compromiso político (su punto de vista es el de los rebeldes al poder español) y (c) film de aventura física, con persecuciones, tiroteos, enfrentamientos de esgrima y escenas de guerra, sólo parangonables al western y a los films de "capa y espada" norteamericanos. A estas líneas de tensión hay que añadirle todavía la del romance, bajo la forma de una aventura galante con una pizca de melodrama (46).

La película también causó impresión y fue un gran éxito de taquilla en su época tras su estreno, con más de cien mil espectadores en 1925 (Bongers 146). Asimismo, la investigadora Alicia Vega subraya dicho éxito citando los comentarios de publicaciones de la época rastreados por Eliana Jara:

Las opiniones de los diarios están sintetizadas en los comentarios de dos críticos bastante severos: "Catón", de La Estrella de Valparaíso, y "Ex", de la revista ZigZag. Dice "Catón": "El filme venía precedido de gran fama: era el mejor filme chileno. La acción se va desarrollando fácil. El argumento no está bien definido. Es más bien la relación de las hazañas de Manuel Rodríguez dentro de las cuales se teje un corto idilio. La fotografía está bien sin ser sobresaliente, aunque hay momentos en que hay cuadros muy precisos. Pedro Sienna está muy bien, tal vez es el mejor trabajo de Sienna [...]" (Jara, cit. en Vega 52).

Los personajes de la película son: Manuel Rodríguez, guerrillero por la Independencia; Carmen, hija del marqués de Aguirre y enamorada de Rodríguez; Huacho Pelao, niño integrante de la guerrilla patriota; San Bruno, capitán realista del Batallón de Talavera; Francisco Casimiro Marcó del Pont, gobernador de Chile; Doña Rosario, dueña de la casa donde se reúnen los patriotas; Charito, hija de Doña Rosario; Sargento Buendía, miembro de la guerrilla; marqués Francisco de Aguirre, realista, dueño de fundo y amigo de San Bruno; El negro, sirviente de la casa del marqués y acompañante de Carmen; José de San Martín, general en jefe del Ejército Libertador; guerrilleros y soldados talaveras.

El argumento del filme (y de la obra teatral) es el siguiente: en 1814, luego de la Batalla de Rancagua, conocido como el Desastre de Rancagua (en que los patriotas no lograron detener el avance del ejército realista comandado por Mariano Osorio hasta Santiago, iniciándose así el periodo de la reconquista española), Manuel Rodríguez figura como líder de los patriotas. Se reúne en Mendoza con San Martín y a su regreso organiza un grupo de patriotas para luchar por la independencia de Chile. Con ellos Rodríguez inicia la guerrilla (agitación y reclutamiento de campesinos, levantamiento de soldados del ejército enemigo, robo de los documentos del gobernador), lo que provoca su persecución por parte de Marcó del Pont y el ejército, lo que Rodríguez 
burla haciendo uso de disfraces, entre otras cosas. En medio de eso, desarrolla una relación amorosa con Carmen, quien pertenece al bando realista. Por otra parte, Rodríguez despierta la admiración del personaje infantil, Huacho Pelao, con quien establece amistad al unirse este a la guerrilla.

Rodríguez vuelve a Mendoza donde San Martín prepara el cruce de Los Andes con el Ejército Libertador. A su regreso, organiza los "Húsares de la muerte", y finalmente resulta asesinado a traición y enterrado por sus amigos.

La estructura dramática del filme está dada por secuencias ordenadas linealmente en las que se representan distintos hechos y anécdotas en torno a la figura de Manuel Rodríguez. Estas acciones son "tratadas a través del establecimiento de un espacio que sirve de escenario para el movimiento de los personajes dentro de un cuadro fijo" (Vega 59). El montaje encadena situaciones por oposición, a través de la acción paralela y de flashback, dándole velocidad y fluidez a los acontecimientos. Como apunta Vega, "El ritmo se logra por la continuidad de la acción y por la insistencia en un tratamiento común de las situaciones a través de toda la película" (59).

$\mathrm{El}$ argumento concluye con la muerte del protagonista, pero esto no se presenta como desenlace de una tensión que hubiese ido en ascenso, sino que es un hecho más dentro de los presentados, como lo plantea Alicia Vega: "De este modo la progresión no está dada por un ascenso del nivel dramático en la que cada secuencia representa un nivel superior de conflicto hasta llegar a un clímax" (55). Todas las secuencias del filme tienen la función de darle heroísmo a Rodríguez.

\section{Antecedentes del Colectivo Artístico La Patogallina y El húsar de la muerte: aproximaciones, transformaciones y creación teatral}

La Patogallina existe desde 1996 y en términos generales se caracteriza por el trabajo colectivo y por la influencia de las tradiciones del teatro físico y el callejero. Su quehacer combina estos elementos junto con aspectos del circo (clown), la música en vivo, la preeminencia de la visualidad por sobre la palabra, el uso de espacios no convencionales como calles y plazas para sus presentaciones (o intervenciones) y el abordaje de temáticas relacionadas con momentos históricos y/o contingencia política.

El origen de la compañía es barrial, emergiendo "desde una posición excéntrica en un campo teatral crecientemente academizado" (Carvajal 61), lo que es poco usual considerando que en general los grupos teatrales en Chile están ligados al espacio universitario (Carvajal y Van Diest 251). Geográficamente, el grupo proviene de la ciudad de Santiago ${ }^{5}$ y se define como "colectivo artístico", lo que no es menor en el

5 Cabe destacar que varios de los primeros integrantes del colectivo crecieron en la misma comuna, Conchalí. Además, 
contexto de la transición ${ }^{6}$ (Carvajal y Van Diest 250), pues esta designación retoma nociones como la horizontalidad, el trabajo de autogestión y la participación, concepciones que fueron casi extintas durante la dictadura.

En concordancia con su autodenominación como colectivo, La Patogallina se caracteriza porque todos sus miembros intervienen en las distintas instancias de la creación de cada espectáculo, en el cual el trabajo autodidacta es fundamental. Para cada obra, se organizan como "autoescuela" en donde los integrantes dictan y participan de talleres (Carvajal y Van Diest 253) con el fin de practicar, adquirir y reformular los saberes necesarios para componer una pieza.

Actualmente el grupo está conformado por actores, músicos, vestuaristas, técnicos en escena, sonidista y director; aunque estas funciones no significan la total especialización de los roles pues, como señalamos, el tipo de trabajo que realizan los lleva a autoformarse para cada nuevo espectáculo según la estética que hayan delineado y/o vayan articulando. La formación de los miembros de la compañía es diversa: algunos son autodidactas y otros provienen de escuelas teatrales no reconocidas por el Ministerio de Educación. ${ }^{7}$ Algunos de sus trabajos más importantes son, además de El húsar de la muerte, 1907, el año de la flor negra (2004) y Extranjero (2011).

El húsar de la muerte se montó por primera vez en el año 2000 en la Cúpula del Parque O'Higgins de Santiago, y su proceso creativo se realizó de forma completamente autogestionada (Carvajal y Van Diest 258). Se ha continuado presentando con éxito hasta la actualidad en diversas ciudades, países y festivales.

Este montaje se convirtió en un referente del teatro nacional, puesto que fusiona elementos expresionistas del cine silente de los años veinte con teatro físico y gestual, un marcado humor, música en vivo y la "utilización de imágenes poéticas y una argumentación tragicómica, [que] les permite parodiar temáticas sociales y políticas de Chile, y llegar a un público masivo a través de sus presentaciones callejeras", de acuerdo con el sitio Chile Escena.

En palabras de la misma compañía, con esta obra ellos pretenden: "1. Rescatar una película y un director que son parte del patrimonio artístico y cultural de nuestro país. 2. Rescatar la figura de Manuel Rodríguez, ese ingenioso guerrillero que se convirtió

varios comenzaron a vincularse artísticamente al reunirse en el Parque Forestal de Santiago, para realizar de forma autodidacta malabarismo y otras actividades ligadas al circo callejero; asimismo, algunos comenzaron a relacionarse antes de fundar el colectivo en grupos políticos y en actividades de autogestión (Carvajal 61). El trabajo político y barrial de la compañía continúa vigente.

6 En Chile, algunos de los hitos iniciales que marcan el proceso de transición son el plebiscito de 1988 y el traspaso del poder político del comandante en jefe de las Fuerzas Armadas, Augusto Pinochet, al presidente electo, Patricio Aylwin, en 1990. Si bien hay quienes circunscriben el proceso entre esos dos años, hay historiadores que sostienen que se trata de un proceso mucho más extenso, esto debido a que se trata de una transición pactada. "Transiciones pactadas significan la continuidad de las estructuras, las elites y las prácticas políticas de los regímenes autoritarios. [...] El caso emblemático es el de Chile, donde el general Augusto Pinochet conservó su puesto de comandante en jefe y luego ocupó una senaduría vitalicia” (Mazzei 11).

7 Como la Escuela Profesional Teatro La Casa, Escuela Teatro Imagen y La Mancha: Escuela Internacional del Gesto y la Imagen. 
en un pilar en la lucha por la independencia de Chile. Por su inagotable imaginación" (cit. en Villegas-Silva 122), objetivos que son logrados en la transposición. Una tercera intención es "Rescatar el teatro de su espacio convencional y pasearlo por las calles, plazas, gimnasios y todos aquellos lugares no habituales al mundo teatral" (cit. en Villegas-Silva 122), lo que ciertamente se condice con la forma en que trabaja el colectivo.

Cabe agregar que el quehacer de La Patogallina corresponde a una práctica artística expandida, en el sentido de que puede trascender a lo espectacular-artístico para acercarse a formas de socialización o acciones ciudadanas o políticas. Justamente, el trabajo de la compañía puede ser analizado como una práctica liminal, de acuerdo con Ileana Diéguez - que considera el concepto de liminalidad propuesto por Victor Turner desde la antropología social-, para pensar aquellas teatralidades "que escapan a las taxonomías tradicionales que han condicionado la teatralidad" (8) "como espacio donde se configuran múltiples arquitectónicas, como una zona compleja donde se cruzan la vida y el arte, la condición ética y la creación estética, como acción de la presencia en un medio de prácticas representacionales" (17). Para Diéguez, las teatralidades liminales están en una zona fronteriza del arte y la vida, y se hallan "inmersas en el 'entre' del tejido cultural y atravesadas por prácticas políticas y ciudadanas" (41), de manera tal que se insertan como acciones sobre el espacio político, social y público. La Patogallina, justamente, realiza un trabajo como colectivo que, además de ser transdisciplinar, puede adquirir el carácter de acciones ciudadanas. La raíz de ello se encontraría, de acuerdo con Fernanda Carvajal, en el origen mixto de la compañía, en donde el barrio y las prácticas militantes y activistas de algunos de sus miembros en los años 80 son fundamentales. Precisamente, la autora examina una presentación específica de El húsar de la muerte como una "intervención política" a la luz de las categorías de liminalidad, performatividad y politicidad. Ella revisa la presentación de la obra en la apertura de la viII versión del Festival Internacional de Teatro a Mil, en 2001, que tuvo lugar al interior de La Moneda. Carvajal observa dicha presentación como un “acontecimiento' inscrito en el espacio social” (75) que se da en medio de la tensión de la "apertura" de La Moneda a la ciudadanía impulsada por el expresidente Ricardo Lagos, la reunión del CosenA en el contexto del juicio a Augusto Pinochet ${ }^{8}$ y la manifestación en los extramuros de la Casa de Gobierno de agrupaciones opositoras a la posible amnistía al exdictador. Para la autora, con esta presentación La Patogallina trae al interior de La Moneda la demanda exigida en los extramuros (pues hizo un breve homenaje a Salvador Allende y los músicos de la compañía hicieron eco de las consignas del afuera), con lo que "convierten [convierte] así el evento teatral en un reclamo ciudadano" (75) y reformula tanto la noción de arte como la de política.

8 El Consejo de Seguridad Nacional (cosena) es una instancia creada por la Constitución Política de 1980 cuyo fin es asesorar al presidente en temas de seguridad nacional. Cuando fue convocado en la oportunidad comentada, los militares buscaban pedir la amnistía a Augusto Pinochet. 
Volviendo a la obra, uno de los elementos característicos de su puesta en escena es la banda en vivo que la musicaliza, la que en el gesto de homenajear al cine mudo funciona como el pianista o la orquesta que acompaña la proyección del filme. La propuesta musical es fundamentalmente rockera pero con mezclas de ritmos funk, cumbia y neofolk.

En términos generales, la obra guarda una proximidad ${ }^{9}$ con la película, en el sentido de que hay una cercanía que se hace evidente a nivel organizativo y, sobre todo, visual; de hecho, hay escenas que han sido recreadas logrando una apariencia semejante. Sin embargo, como iremos viendo, este grado de relación no quiere decir que el montaje teatral sea una ilustración del cinematográfico - que es lo primero que podría pensarse al contrastar someramente ambas creaciones-e incluso veremos que si bien estos parecen ser muy similares, un abordaje más detenido revela que tras ese parecido existen importantes diferencias.

Como mencionamos, a nivel estructural la obra considera el mismo argumento de la película en que, retomando a Vega, se suceden una serie de anécdotas y hechos referidos a o protagonizados por Manuel Rodríguez que si bien siguen una lógica causal de acuerdo a un entramado mayor, no están construidos de una forma tradicional dramática, pues cuentan con autonomía entre sí y no parecen estar enlazados progresivamente hasta llevar a un clímax. De todos modos, estos sucesos se encuentran circunscritos a ciertos momentos histórico-cronológicos, como el Desastre de Rancagua, la Batalla de Maipú y la misma muerte del personaje.

La obra de teatro reordena la disposición de algunas escenas - y ciertamente las reconstruye al transponerlas-, incluye unas pocas y también suprime otras. Estos tres procedimientos, no obstante, no modifican a grandes rasgos la arquitectura del filme, lo que conlleva la proximidad estructural con la película.

El primer y el tercer procedimiento son los más notorios si se comparan ambas obras. Con respecto al tercero, a través de la supresión de ciertas escenas, La Patogallina omite tratar algunos aspectos del argumento del filme para focalizar en uno específico y resemantizarlo. Mayoritariamente, las escenas no consideradas son las que tienen que ver con algunas anécdotas protagonizadas por Manuel Rodríguez y/o los campesinos (como algunas acciones en que participa Charito), con el marqués de Aguirre (quien muere en la película) y con el retrato más detallado de los aristócratas. En primer lugar, al quitarse parte del retrato y las acciones de Rodríguez y los patriotas se reducen algunas acciones y elementos complementarios para así concentrar el argumento. En segundo lugar, al excluirse la participación del marqués, se está optando por quitar un contenido de tono más dramático que además está asociado

9 Nos parece más acertado hablar de "proximidad" en vez de "fidelidad" para expresar la cercanía con la obra cinematográfica. Cid utiliza este término en la sistematización de las modalidades de transposición que propone, aunque no es nuestra intención situar el caso que trabajamos en una de ellas, ni tampoco en la otra clasificación revisada, la de Sánchez Noriega. 
con el personaje de Carmen. Finalmente, al restringirse la aparición de la clase alta y Marcó del Pont (quien aparece someramente en la obra teatral), así como la del mismo marqués, se está minimizando la mostración que la nobleza tiene en el filme y, por ende, su rol como agente sociopolítico en el contexto de la Colonia e Independencia.

La condensación que opera en este tercer aspecto es, a nuestro parecer, la que tiene un mayor impacto o efecto a nivel de sentido. Esto, porque se estaría disminuyendo el papel de la aristocracia para hacer hincapié en otro elemento tan presente en la película como el primero: se trata del rol de los soldados talaveras y de San Bruno, y su papel represivo. Así, si en la película el enemigo, que es la Corona, se despliega a nivel social y militar, en la obra teatral se manifiesta puntualmente a través de las Fuerzas Armadas que violentan y dominan a la población. Se retira a los aristócratas para otorgarle mayor protagonismo a lo militar, y este énfasis influye directamente en volver más actual el contenido de la obra de Sienna. Esto porque la represión policial es un factor contingente en el Chile contemporáneo.

Respecto a la reacomodación de escenas, que también se ve influida por aquellas que fueron suprimidas o agregadas, esta apunta por un lado a agilizar las acciones y por otro a reelaborar el contenido desde lo que a La Patogallina le interesaría destacar del filme y lo que le interesaría rearticular desde la actualidad, que es enfatizar en el sentido político del personaje en el día de hoy.

\section{Manuel Rodríguez y la reivindicación del héroe desde lo popular}

La figura de Manuel Rodríguez ha inspirado a lo largo del siglo xx y parte del xxI una gran variedad de creaciones ligadas al mundo de la cultura. Entre ellas, pueden contarse películas, obras teatrales, poemas, canciones, historietas y un capítulo en una serie de televisión. Esto no hace más que confirmar su presencia en el imaginario nacional y la relevancia del personaje para el público chileno. Si consideramos lo anterior y lo aplicamos en relación con las obras que trabajamos aquí, podemos formular dos preguntas cruciales referidas a cada pieza, respectivamente. Por un lado, la obra de Sienna es una de las tres versiones cinematográficas sobre Manuel Rodríguez que se hicieron a comienzos del siglo xx: una es de la década del 10 y dos son de la década del 20. Teniendo en cuenta además el éxito de taquilla que representó El húsar de la muerte en su momento, cabe preguntarse, primero, ¿por qué el interés por este personaje histórico en este contexto de producción? En segundo lugar, resulta útil interrogarse también por el foco que la misma Patogallina puso en Rodríguez y el reconocimiento que tuvo la obra, ${ }^{10}$ de lo que se desprende lo siguiente: ¿cuál es el interés por Manuel Rodríguez en el trabajo de La Patogallina, considerando nuestra época?

10 La pieza fue rápidamente reconocida dentro del medio teatral, puesto que a menos de un año de su estreno fue escogida para abrir la viII versión del Festival Internacional de Teatro a Mil, en 2001. Con el correr de los años ha sido presentada en distintos festivales en España, Francia, Ecuador, Argentina, Brasil e incluso en India. 
Estas dos preguntas resultan pertinentes para comprender el trabajo de transposición del colectivo artístico y el papel del personaje en aquel. Para desarrollar un análisis que las considere como norte, también es necesario tener muy en cuenta qué representa Rodríguez en las dos obras y en nuestro imaginario, cuáles son los valores que encarna. La directriz de ello, como anticipamos en el título de esta sección, está dada por su vínculo con el mundo popular.

La pregunta sobre el porqué de la recurrencia del héroe en el cine de inicios del siglo pasado ya ha sido elaborada y respondida por Cristian Ahumada y Carolina Kuhlmann en su esclarecedor trabajo "Nación y taquilla. Percepciones sobre la película El húsar de la muerte encontradas en el Chile de 1925”. Los autores plantean que existen motivos propios del contexto histórico en que era importante consolidar o reconfigurar lo que se entendía por nación y sentimiento nacional (centrándose en las costumbres y tradiciones nacionales, instalando nuevas figuras patrióticas). En el arraigo de estos, "el guerrillero"11 juega un importante rol.

A principios del siglo xx, países como Chile llevaban apenas un centenario de independencia, por lo que fortalecer el discurso nacional desmarcándose de la matriz europea y europeizante era propio de la situación de una joven nación latinoamericana. En este sentido, el cine en tanto gran medio es considerado como un agente "civilizador y educativo" (Ahumada y Kuhlmann 14) que puede difundir ideas y contribuir a afianzar el sentimiento patrio. Es el momento, además, en que las huelgas obreras están en auge, de modo que desde la oficialidad se hacen necesarios los discursos que apuntan a la integración a través de la construcción de una identidad propia y a la "sensación de pertenencia a algo común” (Ahumada y Kuhlmann 14). En este marco, Manuel Rodríguez es un sujeto especial, porque concentra varios de los rasgos valorados por el creciente nacionalismo y las masas, de modo que su imagen resulta funcional para reforzar la sensación de unidad. Dichos rasgos tienen una raíz directa en el universo popular, que en este contexto es el campesinado. Así, Rodríguez concentra en sí una idea de "lo chileno" y consiste "tanto en la figura fundadora de la nación, como en el héroe ligado al mundo popular, lo que permite la nueva amalgama nacionalista de la época" (Ahumada y Kuhlmann 16). ${ }^{12}$

Particularmente en la leyenda, pero también en la historia, Rodríguez es sinónimo de rebeldía, libertad, coraje y, sobre todo, patriotismo, y juega efectivamente un papel importante en el proceso de emancipación. A estos rasgos se suman la astucia, la galantería, la jovialidad, el liderazgo y un espíritu dinámico que le permite resolver situaciones hábilmente; como bien señala Jorge Ruffinelli, no es un "prócer adusto

11 Expresión usada en Chile para referirse a Manuel Rodríguez. Su uso probablemente se extiende desde la musicalización de las “Tonadas de Manuel Rodríguez" del Canto General (1950) de Pablo Neruda, por parte de Vicente Bianchi (1955). Cfr. www.memoriachilena.cl para ver los versos (http://www.memoriachilena.cl/602/w3-article-98151.html).

12 De acuerdo con Ahumada y Kuhlmann, es la popularidad de Rodríguez entre la gente la que lo lleva a ser un ícono del nacionalismo, a diferencia de otros próceres más renombrados en la oficialidad como Bernardo O’Higgins y José Miguel Carrera (18). 
sino un aventurero" (50), un sujeto carismático que reúne una serie de atributos que lo convierten en una figura excepcional y atractiva.

Asimismo, lo atractivo de su figura es una de las razones del éxito del filme y de su recurrencia en la producción cinematográfica: a comienzos del siglo xx, Rodríguez ya era de por sí un sujeto interesante para el espectador, conocido y querido por este (Ahumada y Kuhlmann 18): era - y es - un héroe que contaba con "una carga emocional ya creada y conservada en su público cautivo" (Ruffinelli 49). De hecho, cabe agregar que la imagen que se muestra en la película - y en la obra teatral- se acerca más a la que proviene del imaginario colectivo que a la estampa de los libros de historia (Ahumada y Kuhlmann 18). Así, las características de Rodríguez lo hicieron un héroe ideal para el cine, en donde la fórmula que combina drama histórico y comedia (en el caso de Sienna) (Ruffinelli 49) desplegados en aventura, idealismo, acción y melodrama, sería exitosa. Habría que agregar que Pedro Sienna (que interpreta a Rodríguez) era un actor célebre en el teatro y su fama contribuyó también a la buena acogida de la película.

Una de las cualidades fundamentales de la mixtura valórica que señalamos antes (y del espíritu de la época) es el patriotismo. La admiración hacia el héroe tiene que ver también con su amor incondicional a la nación en contraste con la opresión de los españoles. Rodríguez, así, es un héroe político de un marcado romanticismo que está dispuesto a llegar hasta las últimas consecuencias en pos de la libertad, lo que deriva finalmente en su muerte perpetrada a traición. Aquí traición tiene un doble sentido: por un lado, el héroe es mandado a ejecutar por un (ex)aliado y, por otro, lo matan por la espalda, lo que la leyenda popular se ha encargado de recalcar y que se muestra también en las obras analizadas. Precisamente, su final dramático suscita aún más la simpatía de la comunidad (Ruffinelli 49); si a ello se suma que el asesinato proviene de la nueva autoridad que él mismo ayudó a llegar al poder (O’Higgins), el personaje logra más impacto.

Como señalan Ahumada y Kuhlmann, la categoría de raza es otro elemento aglutinante socialmente que entra en juego en el momento en que se estrena la película de Sienna y que puede ser leído en ella. La "raza chilena" se codifica como la identidad del país y recoge a los sectores bajos, los que a su vez se erigen en la figura del "roto chileno". El personaje del Huacho Pelao viene a encarnar esta idea, pues es un niño huérfano y pobre que sigue los ideales de Rodríguez y que admira lo que este representa, mostrando incluso algunos de sus rasgos, como la valentía y la astucia (15), que son parte del ser "roto".

Sin embargo, en la "raza" o en el "roto" también penetra el sujeto popular campesino, que está presente a lo largo del filme (ya que es "lo chileno" a comienzos del siglo XIX, que se mantiene quizás casi intacto a inicios del xx) e, igualmente, articula al Huacho Pelao como personaje. La ruralidad es un elemento preponderante y, como apunta Bongers, en la película se pone el acento en el costumbrismo y se advierte la oposición entre el campo chileno y la cultura española (146). El espacio central del filme es el campo (frontis de casas, calles, caminos, árboles) en el que se despliegan los 
patriotas, quienes son siempre campesinos. Un aspecto que llama la atención es que los patriotas se muestran más en los exteriores, mientras los españoles, en interiores; la excepción de los primeros es el adentro de la casa de Rosario donde la montonera se reúne. Los espacios en que habitan los patriotas son representados como sitios de camaradería, vivacidad e intrepidez y están en la naturaleza/ruralidad, elemento que remite al Romanticismo y a la libertad, igualdad y bondad innata del hombre en el pensamiento moderno (Rousseau). Por el contrario, el interior vinculado a los españoles, que es la casa de Marcó del Pont, se exhibe como aparatoso, cursi y hasta ridículo; ${ }^{13}$ muy distinto de la desenvoltura de los seguidores de Manuel Rodríguez y de este mismo. De hecho, los soldados talaveras y San Bruno son objeto de humor en ambas piezas, aunque de forma mucho más marcada en la obra teatral, lo que se contrapone a la dignidad que muestran los guerrilleros.

Cabe agregar que en el éxito del filme (más allá del interés por el héroe), de acuerdo con Ahumada y Kuhlmann, también influye el carácter comercial del nacionalismo y la adecuación del montaje a elementos melodramáticos y cómicos del modelo de Hollywood, el cual se estaba reproduciendo en el país (19).

El Huacho Pelao es en la película un personaje tan importante como Manuel Rodríguez, lo cual es retomado por La Patogallina; podría afirmarse que son coprotagonistas, ya que las acciones que ejecuta cada uno son centrales en las obras. Este niño encarna al sujeto popular, al converger en él los aspectos ya vistos (el "roto" y el campesino), además de que es quien da el tono de comedia en el bando patriota a través de su astucia. Gracias a ella burla a la autoridad cuando roba la corneta y también cuando sustrae el pollo (esto en el filme).

Asimismo, la escena del volantín es un momento en el que se introduce un componente del mundo popular: el volantín mismo. ${ }^{14}$ En ella, el Huacho Pelao usa este objeto, que le presta otro niño, con el fin de saber si Rodríguez se encuentra herido en una casa. Gracias al volantín, antes juguete y ahora instrumento (cual artefacto de un servicio de inteligencia), el personaje logra saber que el héroe está vivo y comunicarse con él al enviarle el dibujo que lo ilustra con la corneta. El montaje muestra alternadamente a Rodríguez dentro de la casa de Carmen y al niño afuera, mirando hacia el muro y subiendo y bajando el volantín. En la transposición, La Patogallina emula la visualidad de la escena (colores, disposición de personajes y objetos principales como la muralla) y resuelve el montaje de la película que alterna entre el adentro y el afuera al usar el muro, pudiendo mostrar ambos espacios. Asimismo, aquí la compañía repone el motivo de la tradición del volantín como parte del mundo popular. Esto último se enfatiza, creemos, y se actualiza al momento en que la banda en vivo toca la melodía de la canción Luchín (1972) de Víctor Jara. Con la inclusión de esta canción,

\footnotetext{
13 En la obra teatral Marcó del Pont y su casa tienen un papel menor, pero la cursilería puede verse, por ejemplo, en la iglesia.

14 Otro elemento que mantiene la obra en este sentido es, por ejemplo, el mate que toman los patriotas.
} 
y entendiendo que el público conoce la letra, La Patogallina logra un efecto de realce de la cultura del pueblo y de vinculación emotivo-política con la escena: el Huacho Pelao — nótese su nombre genérico- que lucha en el siglo xix está presente en el Luchín de los setenta como esperanza de un futuro sujeto social, y también hoy en día.

Un punto de lo que plantea Jorge Ruffinelli que es imprescindible agregar es el sentido general que para él tiene la película de Sienna. En su artículo, el autor señala que la idea fundamental del filme es que esta es una obra sobre la "conversión revolucionaria" (énfasis del original) (53). Ruffinelli describe pormenorizadamente los episodios en que Rodríguez se disfraza, los cuales ilustran una práctica archirreconocida por la leyenda del héroe y hacen más atractivo al personaje y a la misma narración. No obstante estas transformaciones superficiales, los ideales del héroe se mantienen intactos: su apariencia muta pero no su ser guerrillero ni su convicción. Y si bien Rodríguez no cambia, sí es un agente que genera el cambio en otros. Él "inspira" (énfasis del original) (Ruffinelli 53) a los campesinos, los insta a adoptar el camino de la guerrilla. Esto se aprecia en el episodio en que el héroe convence a un soldado talavera de unirse a los suyos; en una escena en donde un campesino deja su labor para irse con los patriotas; e incluso en Carmen, aliada de los españoles, que se enamora del enemigo de la Corona que ella defiende (Ruffinelli 51-55). Sin embargo, como destaca el autor, la "conversión" más significativa es la que experimenta el Huacho Pelao. El niño decide volverse guerrillero luego de sufrir una paliza por parte de San Bruno, y el tránsito para convertirse en patriota es de "doble movimiento", pues va de "niño a hombre, de juego a realidad" (Ruffinelli 54). Aquí, luego de pedirle a Rodríguez que lo lleve de corneta con la montonera, el robo del instrumento será la prueba por la que deberá pasar el Huacho Pelao para poder ser parte de la guerrilla.

En términos de la transposición, la escena clave en que el niño decide combatir, que comienza como un juego, mantiene las acciones que se presentan en la escena análoga del filme. En ambas, se presenta un grupo de niños que juegan a ser guerrilleros y que son comandados por el Huacho Pelao quien grita (se muestra en los subtítulos) “¡Viva la patria! ¡Viva Manuel Rodríguez! ¡Abajo San Bruno!”. Sin que el improvisado líder se percate, llega San Bruno y los otros niños huyen. El capitán lo lanza al suelo y lo golpea "por patriota". El huérfano se levanta adolorido y pronuncia el texto en que asume que será guerrillero. En la transposición es "Ahora seré un guerrillero de adeveras", mostrado en un cartel. La obra de teatro ubica esta escena más hacia el comienzo en relación con la película, luego de una introducción que explica el contexto histórico-político en que se producen los acontecimientos y que presenta a Manuel Rodríguez como personaje (es el elegido por San Martín para llevar a cabo la misión y es el guerrillero que burla a la autoridad a través del disfraz). Es decir, esta escena abre la "parte argumental" o de secuencia de acciones de la obra, por decirlo de algún modo, y presenta al Huacho Pelao. Una diferencia respecto a la versión cinematográfica de este episodio es que aquí los niños aparecen jugando en caballos de madera, como dejando en claro que se trata de infantes. La disposición de los actores en el espacio, 
el tipo de juego que realizan y cómo lo efectúan, evocan la serie El chavo del ocho, el programa que es un clásico en la cultura popular latinoamericana.

El Huacho Pelao, entonces, es un personaje principal en la película que desarrolla un camino que va en pos de la lucha. Como comenta Alicia Vega, la secuencia remite de manera sintética a lo que ocurre en el filme y es una analogía de la lucha de Rodríguez, en donde la paliza dada por el capitán Talavera es la represión a los rebeldes (56-57). El niño-hombre, por lo tanto, es una metonimia del espíritu revolucionario y del pueblo; en tanto niño, viene a representar a este pueblo dependiente o Colonia, y en tanto adulto ejecuta acciones para emanciparse. Asimismo, el personaje está construido para despertar la simpatía y, desde allí, la identificación del espectador: así como el Huacho Pelao descubre la (cruel) realidad y decide actuar inspirado por Manuel Rodríguez, el público puede sentirse empapado de ese ímpetu. El auditorio, de esta forma, puede verse en el Huacho Pelao, quien abre las acciones de la obra y las cierra al llorar la muerte del héroe al final.

En la obra de La Patogallina, estos aspectos se encuentran latentes, así como también los rasgos asociados al personaje de Manuel Rodríguez. Sin embargo, si bien en el filme se rescata la figura política y popular del héroe $-\mathrm{y}$ los elementos ya señalados respecto al Huacho Pelao - así como su arraigo en el imaginario chileno como sinónimo de rebeldía, romanticismo, astucia y, sobre todo, patriotismo, en la obra teatral estos valores se revitalizan y transforman, desviándose de la exaltación patriótica de Rodríguez y enfatizando su carácter popular y rebelde, lo que tiene una contundente impronta política en el Chile presente. Ello se ve reforzado por los elementos contemporáneos que incluye la obra, como el retrato de Augusto Pinochet con los anteojos oscuros en el despacho de San Bruno, la conversión de O’Higgins en un tirano reforzada porque los sonidos que emite son ladridos (que también recuerda el autoritarismo dictatorial), las menciones en la misa para bendecir a Raúl Hasbún y Fernando Karadima, ${ }^{15}$ los sonidos propios de la música mapuche cuando el tuerto se delata como traidor o el grafiti con la demanda "Educación gratuita"16 en el muro.

En este acento político e ideológico que pone La Patogallina también se encuentra la situación de Rodríguez como sujeto revolucionario que es traicionado por el poder de su época, representado en la figura de Bernardo O’Higgins. Esto a causa de una lectura actualizada que puede hacerse en el contexto de posdictadura, en que la izquierda revolucionaria se ha sentido traicionada por el proceso político llevado

15 Raúl Hasbún es un sacerdote católico, conocido por defender públicamente el régimen militar y las violaciones a los derechos humanos, que condujo espacios de comentarios religiosos en dos canales de televisión entre 1977 y 2012. Fernando Karadima es también un sacerdote católico y fue declarado culpable de abusos sexuales contra menores por una investigación canónica, pero no por la justicia. Seguramente, la mención a Karadima fue incorporada después del 2004, año en que conocieron los sucesos.

16 Es muy probable que esta consigna se haya incluido después de las movilizaciones estudiantiles del 2006 o 2011, en que estudiantes secundarios y universitarios exigieron un cambio en el modelo educativo instaurado durante la dictadura a través de la Ley Orgánica Constitucional de Enseñanza. Esta modificación, así como la mención a Fernando Karadima, permite dar cuenta de la capacidad de la obra y de la compañía para dialogar con la contingencia. 
a cabo tras la transición a la democracia: es preciso tener en cuenta que la figura de Rodríguez inspiró el nombre del grupo de izquierda armada, Frente Patriótico Manuel Rodríguez. ${ }^{17}$ El paralelo puede hacerse con el mismo escuadrón comandado por el héroe en el siglo XIX, los Húsares de la muerte. Estos son, como hemos visto, un grupo armado de campesinos, una guerrilla sin disciplina militar que, no obstante, se rebela contra el poder español. El origen de este grupo es netamente popular, ${ }^{18} \mathrm{y}$ de allí el vínculo con la guerrilla del periodo de la dictadura.

Así, entonces, El húsar de la muerte de La Patogallina reafirma el carácter popular del héroe que existe como sustrato en nuestro imaginario y el del personaje del Huacho Pelao; estos siguen vigentes, asimismo, en nuestra época. Junto con ello, la obra rescata los rasgos valóricos de Manuel Rodríguez y canaliza la abnegación y patriotismo que este representa hacia la condición de sujeto subversivo, político e idealista desde una óptica posdictatorial que mira hacia atrás. En ella, dichos rasgos son valorados pues representan la lucha contra el autoritarismo y al mismo sistema actual producido por aquel; por extensión, tienen un valor universal. Un aspecto más, ciertamente relevante en este sentido, es que el niño es quien cierra la obra luego de la muerte del guerrillero. Finalmente, el Huacho Pelao se erige en un gesto que indica que él continuará con la lucha, consolidando así el llamado a la acción.

\section{Reivindicación de la "memoria cinematográfica" y transposición del lenguaje del cine silente}

\section{Efectos estéticos de la transposición del lenguaje}

Como mencionamos, La Patogallina crea una obra teatral que observa y cita al cine silente, lo que Claudia Villegas-Silva ha denominado "teatralización del cine" (121). Dado que entendemos que ambas obras se relacionan en términos de transposición, nos parece adecuado, más bien, hablar de un movimiento de ida y vuelta entre códigos, en que La Patogallina mira hacia el lenguaje cinematográfico silente y lo recrea a partir del lenguaje teatral. Se trata de un medio que dialoga con el otro y lo rescata para reivindicarlo, como sistema significante y como filme que ha sido olvidado en el tiempo pero que no obstante sigue vigente. El resultado es un espectáculo que asimila y reconfigura ciertos elementos del lenguaje fuente desde el tamiz de las propias preferencias artísticas del colectivo, montaje que, por lo demás, le llevó a consolidar su búsqueda estética (Chile Escena, Memoria activa del teatro chileno) y a afianzar una

17 Inicialmente brazo armado del Partido Comunista chileno. Sus actividades comenzaron en 1983, entre las que se encuentran las operaciones Carrizal Bajo y Siglo xx (ambas en 1986); esta última consistió en un atentado contra el dictador, entonces comandante en jefe y presidente, Augusto Pinochet.

18 Los "Húsares de la muerte" son el escuadrón de guerrilla formado por Manuel Rodríguez, cuyos mandos estaban a cargo de amigos y parientes del héroe. Una vez que O’Higgins asume el poder ordena disolverlos. Para un detalle del origen de los “Húsares", ver Jorge Ruffinelli. 
identidad propia. En la transposición, entonces, tenemos un objeto nuevo y particular en que el sistema teatral remite, se nutre de, y cita explícitamente al cinematográfico, para de hecho simular que se monta el filme, al punto en que ambos sistemas parecen casi sintetizarse con el fin de crear esta "película de teatro", como le ha llamado la misma compañía en el programa de un festival ${ }^{19}$ (cit. en Villegas-Silva 122).

Si bien la premisa adoptada por la compañía es llevar la película a la escena teatral, ello es parte de un juego ficcional. Además, a pesar de que resulta tentadora la idea de que la obra ilustra la película, seguimos considerando la autonomía de cada pieza, la que se ve reforzada en que aunque se desconozca la película de Sienna, la creación de La Patogallina tiene sentido por sí misma.

En vista de todo lo anterior, revisamos algunos elementos de la transposición referidos a lo cinematográfico a través del análisis de ciertas escenas. Estos elementos son: la figura del proyeccionista, el blanco y negro, el iris o cache, los intertítulos y el lenguaje verbal, la gestualidad, el efecto de cámara lenta o ralentí y, lo que se aleja de lo cinematográfico en sí, la música.

La obra se inicia cuando ingresa un personaje en motoneta al espacio teatral que trae el rollo de la película y la instala detrás del público. Es el proyeccionista: figura fundamental de la sala de cine, que habitualmente no vemos. De este modo se establece un pacto lúdico con el espectador de que lo que se verá en escena es un filme. Como señala la misma Patogallina, con ello pretenden hacer sentir la experiencia de encontrarse frente a una película muda: "Cuando la gente se encuentre con nuestro espectáculo, queremos que cierre los ojos por un segundo, los abra y sienta que está en una enorme sala de cine de los años 20; un escenario en donde se proyectará 'la película' [...]" (cit. en Villegas-Silva 123). Así, de entrada el espectador es "avisado" de que el espectáculo consiste en una película muda hecha en el teatro - si se nos permite la licencia en términos expresivos-.

El blanco y negro es algo que caracteriza a la obra, lo que resulta atípico, y se debe a los mismos colores del filme de Sienna. Como espectadores, ver que la escenografía, el maquillaje y el vestuario son en blanco y negro y escala de grises es otro de los elementos que nos introduce en la ficción de este filme "antiguo". Si bien esto se podría considerar como una mera imitación, la apropiación del signo monocromo por parte de la compañía desde el lenguaje teatral se confirma cuando presenciamos que deciden agregar color en algunas escenas de la obra. Así, construyen una relación significativa entre lo monocromático y los colores, dejando el blanco y negro para el plano "realista" y la presencia de colores - en luces y objetos- para escenas oníricas, como en la del sueño del Huacho Pelao que describiremos a continuación.

Antes de entrar en detalles sobre esta escena, cabe mencionar que el vestuario y ciertos elementos de la obra siguen la iconografía del periodo independentista, siempre desde la escala de grises propuesta por la película. Lo que más llama la atención

19 Festival Iberoamericano de Teatro de Cádiz de octubre de 2001. 
es el atuendo de Rodríguez, que retoma el uniforme de los Húsares de la muerte y que hace posible identificarlo de inmediato en escena. Lo mismo ocurre con el brazo entablillado de O’Higgins luego de la Batalla de Maipú. Destaca, también, la calavera blanca sobre el fondo negro de los Húsares, usada luego de la introducción en la obra al mostrarse el título bajo el texto que señala "La Patogallina Cinemascope presenta".

Con respecto a la escena del sueño, en ambas obras, en un momento en que Rodríguez se encuentra con campesinos, llega el Huacho Pelao diciendo que quiere ser corneta, a lo que Rodríguez responde que para ello debe conseguir el instrumento primero. El niño se queda solo, pensando cómo obtenerla. Luego, se muestra la escena en que este imagina la corneta que tanto desea. En la del filme, el niño vence sin problemas a un grupo de realistas y llega Charito a darle el instrumento, y despierta cuando le tiran agua. En la transposición, el huérfano fantasea con ella y su anhelo es "en colores". Se la ve arriba, en el cache, y a unos querubines que tocan en la parte alta de la escenografía. Esta escena nos presenta la ensoñación del joven por la corneta, pasaje onírico en el que surgen colores, plumas y jazz. Mientras, como fantasía e imposibilidad, se le aparece una corneta gigante que no logra obtener, hasta que otro personaje lo despierta del sueño reventando una bolsa de papel, y volvemos al blanco y negro.

La abertura circular a través de la cual se presenta la corneta en la escena anterior, así como algunos personajes y situaciones a lo largo de la obra, emula el cache propio del cine. De acuerdo con Eduardo Russo, el iris o cache "es la cobertura parcial del lente de la cámara que deja ver un recorte del campo visual, con fines diversos" (140). En el filme, la primera vez que se usa el cache es para presentar a un campesino patriota que ha sido objeto de la represión realista, y se lo muestra en un primer plano diciendo: “¡Ya seremos libres y las pagarán todas. perros opresores! [sic]”. Encontramos el uso de esta técnica en escenas muy distintas, como cuando el emisario entrega la carta de Rodríguez en la fiesta de los aristócratas o en el movimiento de cámara que presenta uno a uno el testimonio de los soldados que describen al héroe de maneras diferentes. También en escenas de planos abiertos en los que el cache pretende centrar la atención del espectador en algunos personajes o enfatizar el punto de vista de quien observa en la escena. Ejemplos de esto último son escenas de batalla en que se quiere mostrar a los patriotas en el campo; el contraplano del Huacho Pelao cuando este observa cómo los patriotas se alejan en el camino sin que él pueda unírseles aún; cuando Charito y el niño observan de lejos a un grupo de campesinos que leen el cartel de "Se busca vivo o muerto a Rodríguez" y, luego, cuando el niño se pierde en el camino corriendo con ese mismo cartel en su poder para dar aviso al guerrillero. También se usa esta cobertura en el plano en que Rodríguez recibe en sus manos la corneta que ha conseguido el niño, así como al final de ciertas escenas para ayudar con la transición. Sin embargo, el cache más interesante que se presenta en la película es el que nos muestra la lectura que Rodríguez realiza del afiche "Se busca”, en la que el cache simula ser la vista atenta del personaje, que localiza rápidamente la información que le compete en el afiche. 
En la obra de teatro, esta abertura opera de un modo distinto, esto por el entendido de que en el teatro habitualmente la vista es panorámica y no recortada como en el cine. No obstante, hay un cache que es parte de la escenografía permanente de la obra, pero que es utilizado en ocasiones específicas. Una de ellas, es para mostrar a San Bruno y sus soldados (uno de estos con la corneta): los personajes pasan uno a uno frente a la abertura y miran al público, se asoman por el cache porque están buscando a Rodríguez. Tras ellos aparece el Huacho Pelao, que a su vez está tras la corneta para ser reclutado por los patriotas. El niño se asoma por la abertura pidiendo silencio al público, pues requiere la complicidad de este para obtener el instrumento, hasta que finalmente lo vemos pasar con la corneta y a los soldados persiguiéndolo.

Sin embargo, una vez más el colectivo teatral lleva esos usos más allá de "lo cinematográfico". En la escena en que, tras el robo de armas, Rodríguez se reúne con San Martín, el encuentro entre ellos se realiza en el cache. Y a través del uso de intertítulos que los mismos personajes sujetan por fuera de la abertura, el guerrillero le comunica a San Martín que ha cumplido sus tareas y este le señala que falta "la más importante" de ellas. En ese momento los personajes del cache salen del recorte y la obra se traslada a la parte baja del escenario, en la que se ve a San Bruno abriendo una caja fuerte. Si bien este procedimiento puede relacionarse con el montaje alterno o progresivo, lo destacable es que en cuanto el realista abre la caja, San Martín reaparece en la abertura y señala con su dedo hacia la escena de San Bruno (la que se congela), expresando que necesita "esa" caja de documentos. De este modo, hay una superposición de escenas que además es temporal y espacial, se trata de un efecto de "omnivisión" para acortar distancias y también realizar elipsis, puesto que tras la petición del libertador argentino aparece Rodríguez en la escena de San Bruno y roba la caja de documentos. Luego de ello, cabe destacar el toque humorístico en que ambos héroes se despiden haciendo un juego de manos en el cache.

Otro de los elementos más característicos del cine silente son los intertítulos, que pueden ser "desde simples cartones preferentemente negros con las leyendas en cuestión (comentarios, líneas de diálogo) hasta pequeñas piezas de lo que hoy llamaríamos diseño gráfico" (Russo 139). En el caso de la versión del filme con la que trabajamos - cuyos intertítulos fueron modificados en el curso de las restauraciones-, nos encontramos con cartones negros con letras blancas utilizados para entregar información necesaria para comprender la acción, otros como conclusión de alguna secuencia, pero la mayoría sirven como transiciones, como ejemplifica Vega: "Rodríguez viaja a Mendoza", "Al domingo siguiente", "Mientras tanto" (68), entre otros. No obstante, en general "no están usados para reemplazar una puesta en escena o reiterar algo expresado ya en la imagen” (Vega 67). Por otro lado, los diálogos están escritos sobre la imagen en la parte inferior del cuadro, como subtítulos, lo que permite que no se detenga la acción.

En la obra de teatro se incorporan los intertítulos de dos formas. La primera es como información de contexto, que se presenta en un fondo negro con letras blancas 
tal como en la película; esta es mostrada a través de una estructura que asemeja una pantalla, en la que hay un mecanismo que va deslizando una tela sobre la que está escrita el texto y hace que este avance de abajo hacia arriba tal como aparecen, por ejemplo, los créditos de muchas películas actuales (y de hecho al final de la obra se vuelve a utilizar para presentar los créditos). La segunda forma corresponde a intertítulos estáticos que muestran diálogos. Estos son presentados en un panel de fondo negro con letras blancas y son traídos a escena por los tramoyas, por los personajes (como en el caso anteriormente descrito de San Martín y Rodríguez) o bien se asoman por un costado. Resulta notable la reposición del dibujo que el Huacho Pelao hace de sí mismo con la corneta, así como también la de las palabras pronunciadas por el mismo personaje cuando decide ser guerrillero, que varía de forma mínima respecto a la del filme y que podría verse como una actualización que evoca, como mencionamos, el imaginario de El chavo del ocho, al cambiar la forma "de veras" por "adeveras" ("ahora seré un guerrillero de adeveras") (énfasis nuestro).

En esta división, queremos también referirnos a dos aspectos de lo verbal, que son propios de la propuesta estética de la obra que la distingue del filme. Si bien la obra se presenta como una pieza teatral "silente" como la película de Sienna (razón por la cual utiliza intertítulos tanto para mostrar contextos como diálogos) a la vez se permite introducir lo verbal-oral de dos formas. La primera es por medio de la voz que se le da al clérigo en la escena de la misa en que se conocen Carmen y Rodríguez. Esta escena, que no existe en la película - los personajes se ven por primera vez afuera de una iglesia-, muestra a la aristocracia en una misa en la que al sacerdote se le da una voz y críticamente se le caracteriza de manera jocosa y se le retrata a través de su vínculo con el dinero; la voz que se le da es graciosa pues imita el eco con que reverberan las voces en una catedral. La segunda forma en que se introduce lo verbal de manera silente es a través de la gesticulación exagerada de ciertas palabras hacia el público de manera cómplice, sobre todo de garabatos, que el público logra leer de los labios de los personajes, suscitando así una risa generalizada. Aquí el Huacho Pelao es el mejor ejemplo.

Con respecto a la gestualidad en el trabajo actoral del filme y de la obra, es posible apreciar una distancia significativa. En la película, los gestos se encuentran suavizados, sobre todo si consideramos la grandilocuencia que podría esperarse en una producción silente, a tal punto "que el efecto inmediato es su contraste con el resto de los filmes mudos", rompiendo "con el tradicional énfasis de ademanes de los actores [de este cine]" (Ruffinelli 55). Por su lado, el estilo actoral en la obra de teatro sí presenta una gestualidad y movimientos corporales más marcados y aparatosos, los que recurren a la pantomima, el clown y, fundamentalmente, al mimodrama, que es algo que ha caracterizado el trabajo de la compañía. Sobre los referentes de este estilo, se hace importante remarcar los diversos orígenes y formaciones de los integrantes de la compañía. Primero, tenemos la actividad en el Parque Forestal, que fue un espacio de convergencia y formación en las artes callejeras que nutrieron 
algunos de los trabajos del colectivo, como A sangre e Pato (1996) y el propio Húsar. Junto con ello, cabe recalcar que algunos miembros pasaron por las escuelas de teatro físico ya mencionadas y dos integrantes fundacionales - Gloria Salgado y Sergio Pineda - trabajaron con Mauricio Celedón en el Teatro del Silencio (Carvajal y Van Diest 250); Celedón fue además discípulo de Étienne Decroux y también trabajó con Ariane Mnouchkine.

En lo que respecta al Húsar, junto al lenguaje físico y gestual de los actores que facilita el ser vistos de lejos en espacio abierto o cerrado, y de noche o de día, se encuentran también otros rasgos propios del teatro callejero, como la búsqueda de una cercanía o complicidad con el público, especialmente a través del humor; así, en lugar de representar teniendo siempre en mente la cuarta pared, hay una proximidad más marcada con el espectador. Un ejemplo de esto es la escena en que las fuerzas realistas golpean al Huacho Pelao y este se soba la espalda y "dice" (modulando exageradamente) una frase en la que expresa su enojo con garabatos; mira al público y suscita la risa en este. También pueden considerarse las menciones a la contingencia ya señaladas: las movilizaciones estudiantiles y los casos de pedofilia dentro de la Iglesia católica.

Por otra parte, la cámara lenta o ralentí se utiliza para realizar un efecto de dilatación del tiempo, con distintos fines: los de remarcar la gestualidad o permitir al espectador ver aquello que en tiempo real no alcanzaría a ver. Con respecto a esto es fundamental considerar que la película de Sienna no utiliza el efecto de cámara lenta.

En la pieza teatral hay dos escenas que incorporan este efecto corporal del movimiento, aludiendo al procedimiento cinematográfico; ambas representan momentos de heroísmo de Rodríguez en que este es herido. La primera es colectiva pues presenta a los Húsares acercándose a un pozo mientras huyen de los realistas. La segunda escena resulta en el asesinato de Rodríguez. Aquí hay un particular juego de efectos de velocidad en el que se mezcla el ralentí con la velocidad normal de movimientos, lo que se enfatiza junto con un juego de sombras que separa la secuencia en distintos movimientos, generando de este modo un mayor impacto frente al asesinato y paliza post mortem que dan al protagonista.

La banda de músicos viene a ocupar el lugar de la música del cine silente que acompaña, que en general dependía de un pianista o una orquesta y, más tarde, de grabaciones. Aquí el grupo crea atmósferas, por ejemplo: cuando aparece Marcó del Pont en escena se recrea una melodía cuyo sonido evoca un instrumento antiguo, como un clavicordio; cuando aparecen los niños se interpreta una música infantil; cuando van a ocurrir acciones cruciales en la tarea de la guerrilla, se interpreta música sugestiva. También, la música ocupa el lugar de lo verbal en el momento en que Manuel y Carmen se despiden, ya que se canta un dueto cuya letra muestra lo que expresan los personajes. 


\section{Reivindicación de la materialidad del cine}

En un comienzo consideramos que el colectivo teatral tomaba únicamente elementos propios del lenguaje cinematográfico para transponer el filme de Sienna. Sin embargo, durante el análisis pudimos notar que junto con ello también repone mecanismos que refieren a la materialidad misma de la película a aspectos del soporte. Esto, creemos, se expresa principalmente a través de dos operaciones que hemos llamado "cambio de bobina" y "movimiento/proyección" — que es el que nos parece más relevante-, e incluso podemos considerar dentro de este conjunto al mismo proyeccionista.

Con respecto al cambio de bobina, en la escena del primer encuentro de Carmen y Rodríguez (en la obra teatral), en un momento se detiene la acción y el instante de suspensión de "la imagen" se reitera varias veces y se ve recortada, tal como podría suceder en la proyección fallida de un filme. Los gritos de la banda en vivo dan cuenta de que se habría acabado la cinta, por lo que es necesario que el proyeccionista se acerque y corra con la bobina siguiente.

Por otra parte, la obra integra en el movimiento corporal de los actores el efecto visual de las películas silentes en que la imagen se ve acelerada, el cual es notorio en algunas escenas de la película de Sienna. En la época del cine mudo, los filmes eran rodados según distintas velocidades (normalmente entre 16 y 20 fotogramas por segundo); cuando se adoptó el sonido a finales de los años veinte, la velocidad de filmación y proyección aumentó (a 24 fotogramas por segundo), de manera que para que el movimiento de las producciones antiguas fuera fiel, era necesario hacer coincidir la velocidad de filmación con la de proyección. Cuando esto no ocurría, se producía el efecto visual "tradicional" de las películas silentes, que es al que estamos acostumbrados, en que los movimientos se ven espasmódicos y acelerados (Bordwell y Thompson 189). La Patogallina, entonces, incorpora este efecto de movimiento/ proyección en algunos movimientos del cuerpo; según dos integrantes del grupo se tomó como referencia el trabajo de Charles Chaplin y Buster Keaton (Del Campo 207). Con ello, se contribuye a hacer aún más vívida la sensación de estar ante la pantalla, así como también se refiere a los soportes mismos del cine: filme, proyección, tiempo y movimiento.

En este último apartado, nos parece fundamental señalar que así como el colectivo es capaz de transponer una película con su propio lenguaje teatral recuperando procedimientos del cine, así como representando aspectos del soporte mismo de lo cinematográfico, su propuesta también pone en escena aspectos del soporte teatral. Esto al tener constantemente actores-tramoyas en la obra que develan el artificio teatral, por un lado, pero que al mismo tiempo reafirman el concepto de colectivo y taller que La Patogallina tiene en su trabajo, pues en vez de ocultar los cambios de escena muestran al espectador el trabajo que estas conllevan y cómo todos forman parte de la puesta, lo que está relacionado con la concepción de actor-obrero que el colectivo ha señalado tener (Carvajal y Van Diest 261). 


\section{Conclusiones}

Con El húsar de la muerte, La Patogallina idea y ejecuta un trabajo de transposición en que, en primer lugar, se homenajea al cine silente nacional y específicamente la obra de Pedro Sienna. Como el mismo colectivo señala, hay una intención de rescatar el patrimonio cinematográfico y mostrárselo al público: el afán por “trasladar” al espectador a una sala antigua de cine habla de un interés por difundir y compartir la memoria artística. Llama la atención que en un momento en que muchos creadores optan por técnicas de teatro multimedia, el colectivo mire hacia el pasado (VillegasSilva 125) y retome una estética, una tecnología, un tema.

En esta revalorización del patrimonio, el trabajo de transformación de medios que realiza la compañía propone, en el plano estético, un movimiento de ida y vuelta desde el lenguaje teatral hacia el cinematográfico; allí, se produce una apropiación del código del cine silente para usarlo como sustrato del lenguaje teatral. La obra, de este modo, crea una visualidad próxima a la fuente transpuesta, pero también se encarga de visibilizar al soporte material mismo del cine mudo y usarlo como parte de la obra. La revitalización del cine y de la película de Sienna es llevada a cabo en la copresencia que permite el teatro.

La pieza de La Patogallina, además, retoma la figura de Manuel Rodríguez como héroe popular del periodo independentista, que es parte de la identidad nacional y que se contrapone - desde ya en su misma leyenda- a los héroes oficiales. Esta es tomada sobre todo en su dimensión revolucionaria y desde allí es actualizada de acuerdo con nuestro contexto actual posdictatorial. En este, la represión por parte de los realistas y luego de los soldados una vez que el héroe es marginado, es un factor importante (la cual es destacada en la transposición en comparación al poder político, si se relaciona con el filme), que tiene sentido en nuestra contemporaneidad si se vincula con la represión militar-policial dictatorial y, por qué no, policial en el día de hoy. En este sentido, el espíritu guerrillero de Manuel Rodríguez y del Huacho Pelao es reivindicado como valor que exhorta a una postura crítica del poder y de los discursos oficiales. La invitación de La Patogallina es a repolitizar la colectividad poniendo en valor lo popular.

En el diálogo transmedial que efectúa la compañía con su obra sale a la luz la positiva acogida que tuvo tanto la transposición como la pieza de Sienna de cara a sus respectivos contextos. Mientras en el filme el éxito se vincula con el nacionalismo (Ahumada y Kuhlmann) y la popularidad del héroe, la recepción positiva de la obra teatral puede relacionarse con la misma figura de Rodríguez, la actualización política de esta y los guiños al Chile contemporáneo. No deja de ser menor que la recepción de cada pieza se enmarque en momentos singulares: la cercana celebración del Centenario, con toda la carga de los discursos del patriotismo, y el proceso de la posdictadura, que comportaba la reconstrucción del país. Se trata, así, de obras que dialogan con la (re) construcción de la nación, que acompañan procesos históricos y colectivos, que leen 
y expresan algunas inquietudes de sus sociedades en momentos cruciales de revisión y debate. Ciertamente, el trabajo de La Patogallina apunta en esa dirección al recurrir al imaginario y, desde allí, emplazar al público en un gesto político.

Finalmente, las decisiones estético-ideológicas llevan a componer una obra que logra reponer en valor la obra cinematográfica de Sienna y, en sus operaciones, darle un sentido político-subversivo y comunitario al guerrillero. Retomando las palabras de Adriana Cid, en esto el Húsar de La Patogallina lleva, justamente, su "sello inconfundible", que es el de hacer un teatro popular, de calle, festivo, físico, gestual, ingenioso y político. La obra transpuesta, así, mira a su obra fuente en esa relación "especular e independiente a la vez" para que la re-conozcamos y para crear otra con un nuevo sentido para nosotros.

\section{Referencias}

Ahumada, Cristian y Carolina Kuhlmann. "Nación y taquilla. Percepciones sobre la película El húsar de la muerte encontradas en el Chile de 1925". Revista Comunicación y Medios; Colección Documentos: Actas del coloquio "La historia en el cine chileno de ficción", no 3, 2014, pp. 11-22.

Bongers, Wolfgang. “Des/figuraciones de Manuel Rodríguez y Bernardo O’Higgins entre el cine y la televisión. Una digresión (política) sobre héroes y huachos". Audiovisual y política en Chile, Eds. Claudia Barril, Pablo Corro y José M. Santa Cruz. Santiago de Chile, Arcis, 2014, pp. 141-156.

Bordwell, David y Kristin Thompson. El arte cinematográfico: una introducción. Barcelona, Paidós, 1995.

Carvajal, Fernanda y Camila van Diest. Nomadismos y ensamblajes: Compañías teatrales de Chile 1990-2008. Santiago de Chile, Cuarto Propio, 2009.

Carvajal, Fernanda. "Performatividad, liminalidad y politicidad en la práctica teatral del colectivo La Patogallina". Aisthesis, no 45, 2009, pp. 56-81.

Chile Escena, Memoria activa del teatro chileno. "La Patogallina (1996-...)". Chile Escena, Memoria activa del teatro chileno 1810-2010, s. f., www.chileescena.cl/index. php? seccion=compania\&idColeccion $=46$. Visitado el 18 de agosto de 2017.

Cid, Adriana. "Pasajes de la literatura al cine; algunas reflexiones sobre la problemática de la transposición fílmica”. Letras, no 63-64, 2011, pp. 19-40.

El húsar de la muerte. Dirigida por Pedro Sienna, actuada por Pedro Sienna y Guillermo Barrientos, Andes Film, 1925. Archivo en línea en Cineteca Nacional de Chile.

Del Campo, Javiera. "Actuación cómica en Chile: Evolución y repercusiones en las técnicas actorales actuales”. Memoria para optar al título de Actriz, Universidad de Chile, 2004.

Diéguez, Ileana. Escenarios liminales: teatralidades, performance y política. Buenos Aires, Atuel, 2007. 
Mazzei, Daniel. "Reflexiones sobre la transición democrática argentina”. Revista PolHis, no 7, 2011, pp. 8-15.

Rousseau, Jean Jacques. Emilio o De la educación. Madrid, Alianza, 1998.

Ruffinelli, Jorge. "La aventura y la patria: El Húsar de la Muerte (1925) de Pedro Sienna”. Aisthesis, no 37, 2004, pp. 45-63.

Russo, Eduardo. Diccionario de cine. Buenos Aires, Paidós, 1998.

Sánchez Noriega, José Luis. De la literatura al cine: Teoría y análisis de la adaptación. Barcelona, Paidós, 2000.

Vega, Alicia, editora. Re-visión del cine chileno. Santiago de Chile, Aconcagua - CENECA, 1979.

Villegas-Silva, Claudia. “Tecnologías en escena: Del teatro multimedia al teatro cibernético en España y las Américas”. Tesis para optar al grado de Doctor of Philosophy in Hispanic Languages and Literature, University of California, 2012. Escholarship.org, https://escholarship.org/uc/item/9rb5n7dq\#page-7. Visitado el 10 de julio de 2017.

Wolf, Sergio. Cine / Literatura: Ritos de pasaje. Buenos Aires, Paidós, 2001.

Enviado: 19 de febrero de 2018

Aceptado: 10 de diciembre de 2018 